\title{
ENSAIO DE OPACIDADE E NÍVEL DE RUÍDO DE UM TRATOR AGRÍCOLA ${ }^{1}$
}

\author{
Sergio Santos Gonçalves ${ }^{2}$, Jorge Wilson Cortez ${ }^{3}$, Sálvio Napoleão Soares Arcoverde ${ }^{2}$, Neiton Silva Machado ${ }^{4}$ e \\ Hideo de Jesus Nagahama ${ }^{5}$
}

\begin{abstract}
RESUMO
Objetivou-se com o presente trabalho avaliar a opacidade e o nível de ruído do trator agrícola em função dos horários de trabalho. $\mathrm{O}$ trabalho foi realizado utilizando trator sem cabine, com delineamento experimental inteiramente casualizado (DIC), sendo sete horários de trabalho, com cinco repetições para o fator opacidade e temperatura do óleo do motor. Para o nível de ruído foi utilizado um fatorial, sendo sete horários de trabalho e duas posições de amostragem (no posto do operador e no escapamento) em rotações de marcha lenta e máxima. Os valores de opacidade variaram em função do horário de trabalho, apresentando maiores valores após $12 \mathrm{~h}$, independente da temperatura do óleo. Os valores de opacidade estiveram abaixo do limite estabelecido pelas normas brasileiras, de 2,5 $\mathrm{m}^{-1}$. As menores temperaturas e umidade ambientes proporcionaram menores valores de opacidade. O nível de ruído sofreu influência do horário de trabalho, sendo maior nas primeiras horas do dia, e maior na posição do escapamento do que no posto do operador. Os valores do nível de ruído estiveram acima dos limites estabelecidos pela norma brasileira para oito horas de trabalho sem protetor auricular.
\end{abstract}

Palavras-Chave: fumaça, poluição sonora, temperatura do motor.

\section{ABSTRACT \\ SMOKE OPACITY AND NOISE LEVEL TESTING OF A TRACTOR}

The objective of this study was to evaluate the smoke opacity and the noise level of a tractor in function of the time of operation. The study was conducted using a tractor without cab. We used a completely randomized design with seven testing times and five replicates for smoke opacity and temperature of the engine oil. For the noise level a factorial was used, composed of seven testing times and two sampling positions (at the location of the operator and at the exhaust) at idle and maximum engine speeds. The values of smoke opacity varied according in the time of testing, showing higher values after 12 hours. The smoke opacity values were below the limit established by the Brazilian standards of 2.5 $\mathrm{m}-1$. Environments with lower temperatures and humidity resulted in lower opacity values. Noise level was influenced by the time of testing and was higher at the exhaust location than that of the operator. The noise levels were above the limits established by the Brazilian standard for eight hours of work without hearing protection.

Keywords: Smoke, noise pollution, engine temperature.

\section{Recebido para publicação em 17/10/2012. Aprovado em 26/03/2013.}

1 - Extraído do trabalho de conclusão de curso em Engenharia Agrícola e Ambiental do primeiro autor.

2 - Engenheiro Agrícola e Ambiental, UNIVASF, Juazeiro-BA, sergio_goncalves2@hotmail.com salviounivasf@hotmail.com

3 - Engenheiro Agrônomo, Professor Adjunto, UFGD, Dourados-MS, jorge.cortez@univasf.edu.br

4 - Engenheiro Agrícola Ambiental, Professor Adjunto, UNIVASF, Petrolina-PE, neiton.machado@univasf.edu.br

5 - Engenheiro Agrônomo, Mestre, UNIVASF, Juazeiro-BA, hideo.nagahama@univasf.edu.br

244 REVENG 


\section{INTRODUÇÃO}

O nível de material particulado presente na fumaça é chamado de opacidade da fumaça ou nível de fumaça. O nível de fumaça varia de acordo com a cor da fumaça, quanto mais escura se apresenta a fumaça, maior será o valor da opacidade e do material particulado.

Lopes et al. (2009), ao avaliarem a opacidade do trator (com diesel puro - B0) em função das condições climáticas (temperatura ambiente de 15,2 a $29^{\circ} \mathrm{C}$ e umidade relativa de 94,1 a $31,4 \%$ ) no horário do ensaio $(1,4,7,10,13,16,19$ e $22 \mathrm{~h})$, verificaram que o fator horário foi significativo $e$ que as uma, as quatro e às sete horas a opacidade da fumaça foi menor. Pressupõe-se que esse comportamento aconteceu em função da menor temperatura ambiente e da maior umidade relativa. Os autores evidenciaram, também, que tais fatores naturais contribuem para melhorar a combustão no motor e que às $13 \mathrm{~h}$ e às $16 \mathrm{~h}$ ocorreram os maiores valores de opacidade, influenciados pelas condições climáticas (maior temperatura ambiente e menor umidade relativa do ar). Mello Júnior (2006) verificou maior variação na opacidade da fumaça nos horários com temperatura mais elevada e menor umidade relativa do ar.

Liotti et al. (2010), ao avaliarem a opacidade da fumaça do trator (com diesel puro - B0) em função das condições climáticas (temperatura ambiente de 20 a $25{ }^{\circ} \mathrm{C}$ e umidade relativa de 91,4 a $69,0 \%$ ) na hora do ensaio $(3,6,9,12,15,18,21$ e $24 \mathrm{~h})$, verificaram que o fator horário foi significativo. Os horários das 12 e $15 \mathrm{~h}$ apresentaram resultados com maior valor da opacidade. Nos horários de $6 \mathrm{e}$ $24 \mathrm{~h}$, a opacidade foi menor. Os autores verificaram amplitude térmica de apenas $5{ }^{\circ} \mathrm{C}$, enquanto no trabalho de Lopes et al. (2009) a amplitude foi de $13,8^{\circ} \mathrm{C}$ e no de Mello Júnior (2006) foi de $14{ }^{\circ} \mathrm{C}$.

A emissão da fumaça, opacidade (material particulado), em estudo com trator de potência nominal de 73,6 kW, operando com diesel metropolitano e interior, misturados ao biodiesel de mamona, em sete proporções, reduziu com o acréscimo de biodiesel até B75 (TABILE et al., 2009). Câmara (2009), ao avaliar a opacidade da fumaça do trator de $73,6 \mathrm{~kW}$ de potência nominal no motor, funcionando com biodiesel de dendê, evidenciou redução da opacidade da fumaça, mesmo com apenas 5\% de biodiesel na mistura.
A opacidade é um dos fatores que devem ser avaliados em sistemas produtivos que utilizam máquinas. Além desse fator, o nível de ruído no posto de trabalho é importante na segurança do operador, e também deve ser avaliado. Baesso et al. (2008) ressaltaram que pessoas expostas a 82, 85,88 ou $92 \mathrm{~dB}(\mathrm{~A})$, em uma jornada diária de trabalho ( $8 \mathrm{~h}$ ), perdem $2,5,10$ ou $20 \%$ da audição, respectivamente. Um dos fatores que pode afetar os valores do nível de ruído é a velocidade do vento, que varia de acordo com as condições climáticas, e, quando a mesma for maior que $5 \mathrm{~m} \mathrm{~s}^{-1}$, deve-se utilizar o protetor de vento (ABNT, 1987).

Dewangan et al. (2005), ao realizarem estudos em tratores de pneu com potência nominal de 18,7 e $26,1 \mathrm{~kW}$, verificaram que ocorreu aumento no nível de ruído com o incremento da rotação no motor, bem como da velocidade de trabalho, sendo os valores máximos encontrados de $92 \mathrm{~dB}(\mathrm{~A})$ para a condição parado. Para Aybek et al. (2010), ao estudarem o nível de ruído em tratores, com e sem cabine, em diferentes operações, verificaram que o nível de ruído foi maior na operação de aração e na colheita de forragem, permitindo uma exposição máxima de $2 \mathrm{~h}$.

Diante do exposto objetivou-se com o presente trabalho avaliar a opacidade e o nível de ruído de um trator agrícola em função dos horários de trabalho.

\section{MATERIAL E MÉTODOS}

O trabalho foi conduzido na Universidade Federal do Vale do São Francisco (UNIVASF), em Petrolina (PE), no Campus Ciências Agrárias, localizado na latitude de $09^{\circ} 23^{\prime}$ sul, longitude de $40^{\circ} 30^{\prime}$ oeste e altitude de 393 m. Segundo a classificação de Köppen, apresenta clima tropical semiárido, tipo BshW, caracterizado pela escassez e irregularidade das precipitações, com chuvas no verão e forte evaporação em consequência das altas temperaturas.

Como fonte de potência, foi utilizado um trator da marca Valtra, modelo 785 TDA (Tração Dianteira Auxiliar), com 55,2 kW (75 cv), fabricado em 2004, com 3.100 horas de uso, com pneus dianteiros 12.4-24 R1 e traseiros 18.4-30 R1, e rotação de trabalho no motor a $2.040 \mathrm{rpm}$. 
A temperatura do óleo do motor foi medida por meio de um termopar, cujo encapsulador é dotado de um limitador de profundidade do carter (óleo do motor), ligada ao controlador serial da marca Tecnomotor (TM616), cuja comunicação dos equipamentos foi feita por meio de uma porta serial ligada ao microcomputador (TECNOMOTOR, 2010). O controlador serial possui uma pinça indutiva para ligar-se ao tacômetro e coletar os dados referentes à rotação do motor. Assim, a rotação do motor foi medida utilizando-se um tacômetro universal, da marca Tecnomotor (TM525/2), sendo feitas leituras de rotação entre 300 a 9990 rpm (TECNOMOTOR, 2007c), cujo sinal elétrico (da rotação do motor) foi obtido por meio da bateria, utilizando o ripple do alternador, no qual as garras do cabo de alimentação foram acopladas aos terminais de bateria (positivo-positivo / negativo-negativo). Para coletar e medir os dados de opacidade, com medições em K (coeficiente de absorção de luz), utilizou-se um opacímetro de fluxo parcial, da marca Tecnomotor (TM133) (TECNOMOTOR, 2007a). Tanto o opacímetro como o controlador serial funcionaram auxiliados pelo software de inspeção veicular da Tecnomotor, denominado IGOR $^{\circledR}$ (TECNOMOTOR, 2007b), instalado ao microcomputador.

Para medir o nível de ruído emitido pelo trator, utilizou-se um decibelímetro digital Homis - modelo 913 (H004-353), que possui três faixas de medição: 30-70 dB; 60-100 dB e 90-130 dB, com Padrão IEC61672, tipo 1 (classes 1 e 2), sem protetor de vento (HOMIS, 2009).

Foi utilizado o delineamento inteiramente casualizado (DIC), em sete horários de execução do ensaio (Quadro 1), sendo às 6h:30min.; 9h:30min.; 10h:30min.; 12h; 13h:30min.; 16h e 18h, com cinco repetições.

O nível ruído foi avaliado no esquema fatorial $(2 \times 7)$, sendo duas posições e sete horários de trabalho (Quadro 1) no delineamento inteiramente casualizado (DIC), e cinco repetições. As posições foram no posto do operador e próximo ao escapamento, com as rotações de marcha lenta (900 rpm) e máxima do motor (2500 rpm).

Antes da realização da coleta de dados, em cada horário de trabalho, o trator ficou em funcionamento por quinze minutos para aquecimento do motor. A aferição da temperatura do óleo do motor, no momento do ensaio, foi feita utilizando um termopar com cabo ligado ao controlador serial, e um computador portátil com o software. A sonda de temperatura foi colocada no orifício da vareta de inspeção do nível de óleo do motor. A rotação do motor foi mensurada com o auxílio de tacômetro ligado à bateria do trator e ao controlador serial por meio de pinça indutiva.

$\mathrm{O}$ ensaio de material particulado ou opacidade é chamado de "Ensaio de Aceleração Livre" conforme a norma NBR 13037/1993 (ABNT, 1993). O opacímetro de fluxo parcial coletou o gás do escapamento e realizou a medição da opacidade por meio de um tubo de captação de uma sonda, montados no cano de escape do trator.

A avaliação do ruído baseou-se no método descrito na NBR-9999 (ABNT, 1987). De acordo com essa norma, no momento do ensaio de medição do nível de ruído, a temperatura ambiente deve estar entre -5 e $30{ }^{\circ} \mathrm{C}$ e a velocidade do vento deve ser inferior a $5,0 \mathrm{~m} \mathrm{~s}^{-1}$.

Para medir o nível de ruído no posto do operador, colocou-se o decibelímetro próximo ao ouvido do operador, $79 \mathrm{~cm}$ acima, com recuo de $15 \mathrm{~cm}$ e afastado $20 \mathrm{~cm}$ lateralmente, paralelo ao ponto de referência do assento (SIP - Seat Index Point), de acordo com a norma NBR 5353 (ABNT, 1999). Dessa forma, o microfone foi instalado do lado da cabeça do operador submetido ao nível ruído (MIALHE, 1996). Foi utilizado o decibelímetro conforme MTE (2010a) nos circuitos de resposta lenta (SLOW) e de equalização "A", sendo expresso em decibéis.

Para medir o nível de ruído próximo ao escapamento, adaptou a metodologia descrita na NBR-9714 (ABNT, 2000), que se refere à medição de ruído nas proximidades do escapamento, em que define o posicionamento do microfone, sendo tomadas as medidas de ruídos em $\mathrm{dB}(\mathrm{A})$, com circuito de resposta lenta, na condição de marcha lenta (900 rpm) e rotação máxima (2500 rpm).

Realizou-se análise de variância para todas as avaliações. Aplicou-se o teste de Tukey para comparação de médias quando foram significativas no teste "F", a 5\% de probabilidade. Realizou-se análise de regressão polinomial ortogonal quando os fatores quantitativos foram significativos pelo teste "F", a $5 \%$ de probabilidade. 
Quadro 1. Dados climatológicos no horário de trabalho (Petrolina, PE, 2011).

\begin{tabular}{lcccc}
\hline Horas & $\begin{array}{c}\text { Pressão atmosférica } \\
(\mathrm{KPa})\end{array}$ & $\begin{array}{c}\text { Velocidade do vento } \\
\left(\mathrm{m} \mathrm{s}^{-1}\right)\end{array}$ & $\begin{array}{c}\text { Temperatura } \\
\text { ambiente }\left({ }^{\circ} \mathrm{C}\right)\end{array}$ & $\begin{array}{c}\text { Umidade relativa do } \\
\text { ar }(\%)\end{array}$ \\
\hline $6: 30$ & 98 & 3,2 & 20,1 & 82,5 \\
$9: 30$ & 98 & 4,5 & 22,9 & 65,5 \\
$10: 30$ & 98 & 4,5 & 25,4 & 53,6 \\
$12: 00$ & 98 & 4,3 & 26,4 & 49,4 \\
$13: 30$ & 98 & 4,4 & 27,9 & 43,5 \\
$16: 00$ & 97 & 3,8 & 29,3 & 37,6 \\
$18: 00$ & 97 & 2,9 & 28,0 & 40,4 \\
\hline
\end{tabular}

\section{RESULTADOS E DISCUSSÃO}

O índice de fumaça, opacidade (Quadro 2), foi menor $(\mathrm{p} \leq 0,01)$ nas primeiras horas de trabalho (6h:30min.; 9h:30min. e 10h:30min.), variando de 0,92 a $0,94 \mathrm{~m}^{-1}$. No momento destas avaliações, verificou-se que ocorreu temperatura ambiente máxima de $25,4^{\circ} \mathrm{C}$ e umidade relativa do ar maior que 50\%. Para Lopes et al. (2009), os menores valores variaram de 1,21 a $1,28 \mathrm{~m}^{-1}$, e para Liotti et al. (2010), utilizando diesel puro, de 0,89 a $1,00 \mathrm{~m}^{-1}$, quando a ocorrência da menor temperatura ambiente aconteceu nas primeiras horas da manhã.

A partir de 12 horas (Quadro 2), verificaramse maiores valores de opacidade, variando de 1,03 a $1,04 \mathrm{~m}^{-1}$, e no momento destas avaliações ocorreram temperaturas ambiente acima de $25^{\circ} \mathrm{C}$ e umidade relativa do ar menor que 50\%. Para Lopes et al. (2009), os maiores valores variaram de 1,37 a $1,48 \mathrm{~m}^{-1}$, e para Liotti et al. (2010), utilizando diesel puro, de 1,03 a $1,18 \mathrm{~m}^{-1}$ nas horas mais quentes do dia, maior temperatura ambiente, com a menor umidade relativa do ar.

Os valores de opacidade atingiram valores máximos de $1,04 \mathrm{~m}^{-1}$ quando acrescentado $5 \%$ de biodiesel no diesel. Quando comparado com os dados de opacidade para o diesel puro, Câmara (2009) encontrou $1,13 \mathrm{~m}^{-1}$, Lopes et al. (2009) encontraram 1,48 $\mathrm{m}^{-1}$ e Liotti (2010) encontrou $1,18 \mathrm{~m}^{-1}$, sendo estes os valores máximos encontrados nos ensaios. Trabalhos de pesquisa demonstram que a opacidade da fumaça reduz com o acréscimo de biodiesel no diesel (TABILE et al., 2009). Câmara (2009) verificou que a opacidade da fumaça apresentou redução, mesmo com apenas 5\% de biodiesel na mistura. Barbosa (2007) verificou que a opacidade da fumaça, apresentou redução de 35\% de B75 comparado com B0.

Os níveis de opacidade (Quadro 2) são comparados a resolução do CONAMA n ${ }^{\circ} .251$ de 1999 (CONAMA, 1999) e verifica-se que, neste caso, o trator estaria aprovado caso fosse aplicado o teste de emissão, pois está abaixo de $2,5 \mathrm{~m}^{-1}$. A redução da opacidade é explicada pela ausência de enxofre no biocombustível, pois o enxofre compartilha o oxigênio disponível na fase tardia da combustão com o carbono resultante da queima parcial, aumentando a produção de material particulado (MAZIERO et al., 2006).

A temperatura do óleo do motor foi maior $(\mathrm{p} \leq 0,01)$ às $16 \mathrm{~h}$ e menor às $13 \mathrm{~h}: 30 \mathrm{~min}$ (Quadro 2). Este fato pode estar associado ao próprio aquecimento do motor que, em todas as análises, ficou por quinze minutos em $2000 \mathrm{rpm}$ de aceleração antes das avaliações. Pode-se notar que às 16 horas e às $13 \mathrm{~h}$ : $30 \mathrm{~min}$ obteve-se o mesmo valor de opacidade $\left(1,04 \mathrm{~m}^{-1}\right)$, condição em que se obteve o maior e menor valor de temperatura do óleo, respectivamente. Dessa forma, a temperatura do óleo do motor não interfere no valor de opacidade.

A análise de regressão polinomial para opacidade e temperatura do óleo apresentou comportamento de terceiro grau, sendo estes modelos com os maiores valores de correlação. No entanto, verificou-se que a regressão para a temperatura do óleo do motor apresentou $\mathrm{R}^{2}$ de 0,06 , ou seja, esse modelo explica apenas $6 \%$ dos casos, e por este motivo não se construiu o gráfico de regressão. Portanto, selecionou-se o modelo de terceiro grau para a opacidade. 
Quadro 2. Síntese da análise de variância dos valores médios de opacidade e temperatura do óleo do motor em função do horário de trabalho (Petrolina, PE, 2011).

\begin{tabular}{ccc}
\hline Fator (Horas) & Opacidade $\left(\mathrm{m}^{-1}\right)$ & Temperatura $\left({ }^{\circ} \mathrm{C}\right)$ \\
\hline $6: 30$ & & $72,60 \mathrm{CD}$ \\
$9: 30$ & $0,93 \mathrm{~B}^{1}$ & $79,40 \mathrm{~A}$ \\
$10: 30$ & $0,92 \mathrm{~B}$ & $73,20 \mathrm{BC}$ \\
$12: 00$ & $0,94 \mathrm{~B}$ & $74,20 \mathrm{~B}$ \\
$13: 30$ & $1,03 \mathrm{~A}$ & $70,40 \mathrm{E}$ \\
$16: 00$ & $1,04 \mathrm{~A}$ & $80,00 \mathrm{~A}$ \\
$18: 00$ & $1,04 \mathrm{~A}$ & $72,00 \mathrm{D}$ \\
\hline TESTE DE F & $1,03 \mathrm{~A}$ & \\
\hline Hora & & $268,00 * *$ \\
\hline CV & $29,83 * *$ & 0,68 \\
\hline
\end{tabular}

${ }^{(1)}$ Médias seguidas de mesma letra na coluna não diferem pelo Teste de Tukey. ${ }^{\text {ns: }}$ não significativo $(\mathrm{p}>0,05) .{ }^{*}, * *$ : significativo $(\mathrm{p} \leq 0,05)$ e significativo $(\mathrm{p} \leq 0,01)$, respectivamente. $\mathrm{CV}$ : coeficiente de variação $(\%)$.

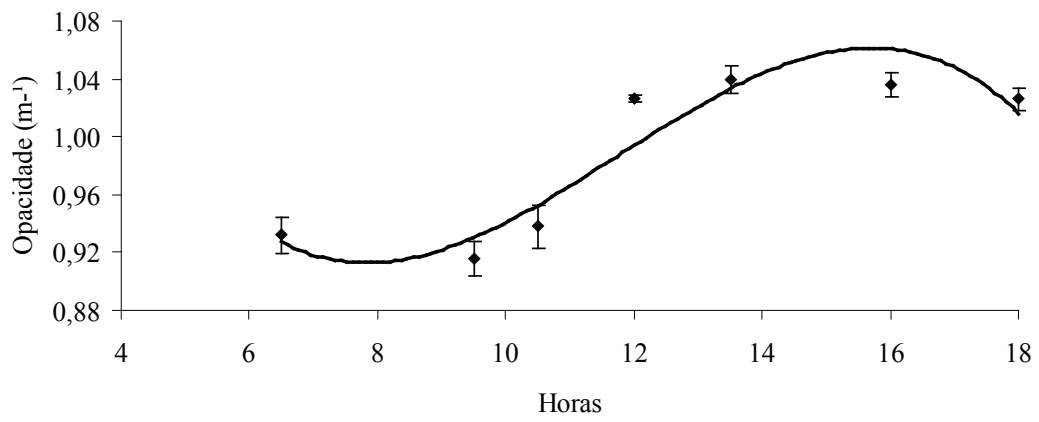

Figura 1. Regressão polinomial para opacidade em função do horário de trabalho. Barras verticais nos pontos indicam o erro padrão da média. Equação: $y=-0,0006 x^{3}+0,02 x^{2}-0,22 x+1,64$ e $R^{2}=$ 0,88 (Petrolina, PE, 2011).

O gráfico de regressão para a opacidade (Figura 1) indica que nas primeiras horas do dia os valores são menores $\left(0,92-0,94 \mathrm{~m}^{-1}\right)$ em virtude, provavelmente, das condições climáticas como temperatura ambiente e umidade relativa do ar. Segundo Lopes et al. (2009), a menor temperatura ambiente e a maior umidade relativa contribuem para melhorar a combustão no motor. Na parte da tarde (a partir das $12 \mathrm{~h}$ ) ocorrem os maiores valores de opacidade $\left(1,03-1,04 \mathrm{~m}^{-1}\right)$, que podem estar relacionados tanto com os maiores valores de temperatura ambiente, como com a baixa umidade relativa do ar $(<50 \%)$.

A amplitude térmica neste trabalho foi de 9,2 ${ }^{\circ} \mathrm{C}$ (a maior $29,3{ }^{\circ} \mathrm{C}$ e a menor $20,1{ }^{\circ} \mathrm{C}$ ). Liotti et al. (2010) verificaram que, com uma amplitude de $5{ }^{\circ} \mathrm{C}$, ocorreu redução da opacidade quando comparados com dados de Mello Júnior (2006), em que ocorreu variação de temperatura de 14 ${ }^{\circ} \mathrm{C}$. Liotti et al. (2010) afirmam que com a queda da temperatura ambiente e aumento da umidade relativa do ar ocorre redução da opacidade, fato ocorrido neste trabalho.

Observou-se (Quadro 3) que o ruído (R) na posição do escapamento foi maior que no posto do operador $(p \leq 0,01)$. Em rotação de marcha lenta, verifica-se diferença de $10,43 \%$ entre o ruído no escapamento e no posto do operador. Na rotação máxima, verificou-se diferença de $4,79 \%$ no ruído no escapamento em relação ao posto do operador. Considerando a norma regulamentadora NR15 (MTE 2010a), os níveis de ruídos estão acima dos

\section{REVENG}


limites permitidos pela legislação para exposição diária de oito horas, sem proteção auricular. Este fato também foi observado por Arcoverde et al. (2011), onde, para um trator agrícola de $55,2 \mathrm{~kW}$ (75 cv), em condições de solo coberto e preparado para diferentes velocidades, em qualquer situação, os valores do nível de ruído foram acima do limite estabelecido pela norma reguladora. Verificase, para ambas as rotações (Quadro 3), que ocorre significância $(\mathrm{p} \leq 0,01)$ para a interação posição x horário de trabalho, sendo desdobrada posteriormente no Quadro 4.

Com relação ao horário de trabalho, pode-se verificar que os maiores valores de ruído (Quadro 4) foram observados no horário inicial (6h:30 min.), condição em que ocorria a menor velocidade do vento e a menor temperatura ambiente. De acordo com os dados (Quadro 4), observa-se pequeno decréscimo nos valores de ruído no escapamento em rotação de marcha lenta (RMLE). Em relação aos valores de rotação no posto do operador, foi observada a mesma tendência seguida nos valores de ruído próximo ao escapamento, com a máxima registrada às 06h:30min. e a mínima às $18 \mathrm{~h}$, com os seguintes valores: 93,82 e 90,32 dB(A), respectivamente.

Considerando a norma NR15 (MTE 2010a), os níveis de ruídos estão acima dos limites permitidos pela legislação para exposição diária de oito horas, sem proteção auricular. Sem proteção auricular, os níveis médios apresentados no posto do operador, de 91,56 dB(A) - marcha lenta e 103,31 $\mathrm{dB}(\mathrm{A})$ - rotação máxima, permite exposição de, aproximadamente, $03 \mathrm{~h}: 38 \mathrm{~min}$. Se considerar os valores máximos obtidos às $06 \mathrm{~h}$ : $30 \mathrm{~min}$., em marcha lenta e máxima, 99,44 e 108,10 dB(A), respectivamente, obter-se-ia uma exposição máxima de 1h:20min. Para uma exposição de 8 horas de trabalho com os níveis apresentados, deve-se utilizar protetores auriculares, como citados na NR-6 (MTE, 2010c), que podem ser circum-auricular, de inserção ou semi-auricular.

Verifica-se que o ruído em rotação de marcha lenta no escapamento foi maior do que no posto do operador em todas as horas, como verificado também na rotação máxima (Quadro 4). Às 06h:30min., verificou-se o maior valor do ruído, tanto no escapamento como no posto do operador (Quadro 4), que pode estar relacionado a menor temperatura ambiente e velocidade do vento. $\mathrm{O}$ menor valor do ruído foi observado às $16 \mathrm{~h}$ para o escapamento e para o posto do operador. Às 16h ocorreu a maior temperatura ambiente, conforme os dados do Quadro 1. Verificou-se, pela análise de regressão polinomial para o ruído no escapamento, que o polinômio de terceiro grau foi o que apresentou maior significância e maior coeficiente de correlação, e por isso foi selecionado para construção da curva de ajuste. Verificouse que a análise de regressão polinomial para o nível de ruído no posto do operador apresentou significância para o modelo de terceiro grau, em rotação de marcha lenta, e de primeiro grau para a rotação máxima. Consequentemente, os maiores coeficiente de determinação foram nestes níveis, e assim selecionou-os para construção do gráfico de regressão.

O gráfico de regressão (Figura 2) apresenta os modelos selecionados para o ruído no escapamento e no posto do operador em função do horário de trabalho. Verificou-se que há diminuição do ruído com a mudança do horário, fato que pode estar associado a maior temperatura e velocidade do vento, e também à umidade relativa do ar.

Quadro 3. Síntese da análise de variância dos valores médios do nível de ruído em marcha lenta e rotação máxima em função do horário de trabalho e da posição no trator (Petrolina, PE, 2011).

\begin{tabular}{lcc}
\hline Fatores & $\begin{array}{c}\text { Nivel de ruído em rotação de } \\
\text { marcha lenta }\end{array}$ & Nível de ruído em rotação máxima \\
\hline TESTE DE F & $3193,6^{* *}$ & $1612,86^{* *}$ \\
\hline Posição (P) & $35,39^{* *}$ & $48,72^{* *}$ \\
Horário (H) & $7,82^{* *}$ & $6,07^{* *}$ \\
P x H & 0,81 & 0,51
\end{tabular}

${ }^{(1)}$ Médias seguidas de mesma letra na coluna não diferem pelo Teste de Tukey. ${ }^{\text {ns: }}$ não significativo (p>0,05). * ${ }^{* *}$ : significativo ( $\mathrm{p} \leq 0,05)$ e significativo ( $\leq 0,01)$, respectivamente. $\mathrm{CV}$ : coeficiente de variação (\%). 
Quadro 4. Síntese do desdobramento da interação para os valores médios do nível de ruído em rotação de marcha lenta e máxima em função da posição e do horário de trabalho (Petrolina, PE, 2011).

\begin{tabular}{cccc}
\hline $\begin{array}{c}\text { Fator } \\
\text { (Horas) }\end{array}$ & $\begin{array}{c}\text { Nível de ruído no } \\
\text { escapamento }\end{array}$ & $\begin{array}{c}\text { Nível de ruído no posto } \\
\text { do operador }\end{array}$ & Média \\
\hline \multicolumn{4}{c}{ Rotação de marcha lenta } \\
$6: 30$ & $93,8 \mathrm{Ab}$ & $99,44 \mathrm{~A}$ \\
$9: 30$ & $105,6 \mathrm{Aa}^{(1)}$ & $92,1 \mathrm{Bb}$ & $97,98 \mathrm{~B}$ \\
$10: 30$ & $103,8 \mathrm{ABa}$ & $90,8 \mathrm{BCb}$ & $96,60 \mathrm{C}$ \\
$12: 00$ & $102,36 \mathrm{BCDa}$ & $91,5 \mathrm{BCb}$ & $97,02 \mathrm{BC}$ \\
$13: 30$ & $102,5 \mathrm{BCa}$ & $91,5 \mathrm{BCb}$ & $96,22 \mathrm{C}$ \\
$16: 00$ & $100,92 \mathrm{Da}$ & $90,7 \mathrm{BCb}$ & $94,76 \mathrm{D}$ \\
$18: 00$ & $98,8 \mathrm{Ea}$ & $90,3 \mathrm{Cb}$ & $96,21 \mathrm{C}$ \\
Média & $102,1 \mathrm{CDa}$ & $91,56 \mathrm{~b}$ & --- \\
& $102,22 \mathrm{a}$ & Rotação máxima & $108,1 \mathrm{~A}$ \\
$6: 30$ & $111,32 \mathrm{Aa}{ }^{(1)}$ & $104,82 \mathrm{Ab}$ & $106,8 \mathrm{~B}$ \\
$9: 30$ & $109,80 \mathrm{Ba}$ & $103,78 \mathrm{ABb}$ & $105,8 \mathrm{CD}$ \\
$10: 30$ & $108,24 \mathrm{Ca}$ & $103,34 \mathrm{BCb}$ & $105,9 \mathrm{C}$ \\
$12: 00$ & $108,38 \mathrm{Ca}$ & $103,56 \mathrm{Bb}$ & $105,07 \mathrm{DE}$ \\
$13: 30$ & $107,12 \mathrm{DEa}$ & $103,02 \mathrm{BCDb}$ & $104,53 \mathrm{E}$ \\
$16: 00$ & $106,82 \mathrm{Ea}$ & $102,24 \mathrm{Db}$ & $105,19 \mathrm{DE}$ \\
$18: 00$ & $107,94 \mathrm{CDa}$ & $102,44 \mathrm{CDb}$ & --- \\
Média & $108,51 \mathrm{a}$ & $103,31 \mathrm{~b}$ & \\
\hline
\end{tabular}

(1) Médias seguidas de mesma letra minúscula na linha e maiúscula na coluna não diferem entre si pelo teste de Tukey a $5 \%$ de probabilidade.

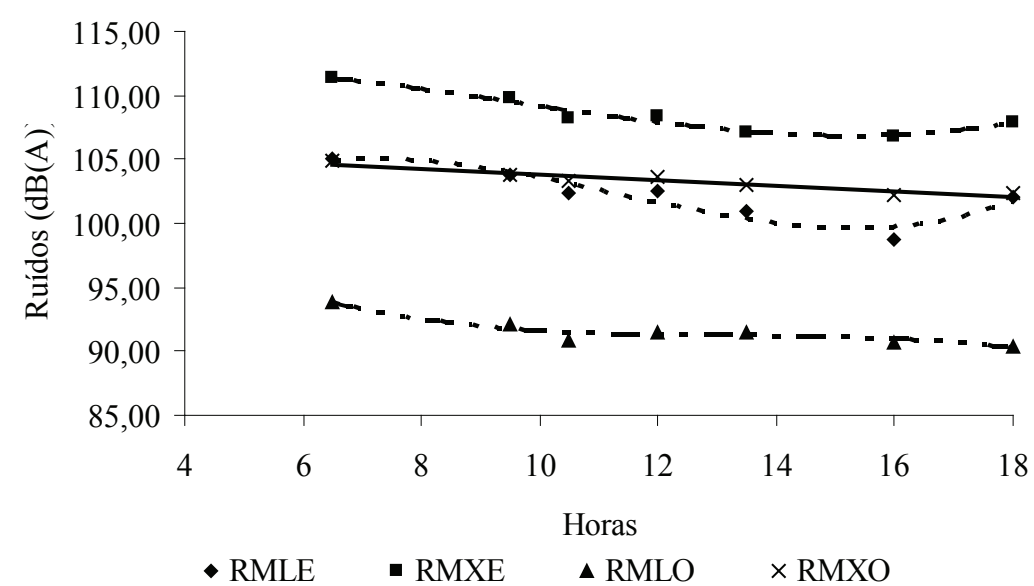

Figura 2. Nível de ruído no escapamento (RMLE - rotação em marcha lenta e RMXE - rotação máxima) e no posto do operador (RMLO - rotação em marcha lenta e RMXO - rotação máxima) em função das condições climáticas no horário de trabalho. Equações: RMLE - $Y=0,02 x^{3}-0,76 x^{2}+7,6 x+81,41$ e $\mathrm{R}^{2}=0,90 ; \mathrm{RMXE}-\mathrm{Y}=-0,21 \mathrm{x}+105,90$ e $\mathrm{R}^{2}=0,90 ; \mathrm{RMLO}-\mathrm{Y}=-0,007 \mathrm{x}^{3}+0,3 \mathrm{x}^{2}-4,06 \mathrm{x}+109,5$ e $\mathrm{R}^{2}=0,90$; RMXO - Y = -0,21x $+105,90$ e $\mathrm{R}^{2}=0,90$ (Petrolina, PE, 2011). 


\section{CONCLUSÕES}

- Os valores de opacidade variaram em função do horário de trabalho.

- A opacidade não depende da temperatura do óleo do motor.

- O nível de ruído variou em função do horário de trabalho e foi maior na posição do escapamento do que no posto do operador.

- Os valores do nível de ruído estiveram acima dos limites estabelecidos pela norma brasileira para oito horas de trabalho sem protetor auricular.

\section{AGRADECIMENTOS}

Os autores agradecem a Universidade Federal do Vale do São Francisco - UNIVASF, especialmente a Seção de Apoio às Atividades de Campo.

\section{REFERÊNCIAS BIBLIOGRÁFICAS}

ARCOVERDE, S.N.; CORTEZ, J.W.; PITANGA JÚNIOR, C.O.; NAGAHAMA, H.J. Nível de ruído emitido por conjuntos mecanizados em função da velocidade e da condição do solo. Revista Brasileira de Ciências Agrárias, Recife, v.6, n.3, p.514-520, 2011.

ASSOCIAÇÃO BRASILEIRA DE NORMAS TÉCNICAS - ABNT. NBR 9999: Medição do nível de potência sonora, no posto de operação de tratores e máquinas agrícolas. Rio de Janeiro, 1987. 21p.

ASSOCIAÇÃO BRASILEIRA DE NORMAS TÉCNICAS - ABNT. NBR-13037 - Gás de Escapamento Emitido por Motor Diesel em Aceleração Livre - Determinação da Opacidade Método de Ensaio. Rio de Janeiro: 1993. 4p.

ASSOCIAÇÃO BRASILEIRA DE NORMAS TÉCNICAS - ABNT. NBR NM-ISO 5353: Máquinas rodoviárias, tratores e máquinas agrícolas e florestais - ponto de referência do assento. Rio de Janeiro: 1999. 5p.
ASSOCIAÇÃO BRASILEIRA DE NORMAS TÉCNICAS - ABNT. NBR-9714 - Veículo rodoviário automotor - Ruído emitido na condição parado. Rio de Janeiro: 2000. 6p.

AYBEK, A.; KAMER, H.A.; ARSLAN, S. Personal noise exposures of operators of agricultural tractors. Applied Ergonomics, London, v.41, p.274-281, 2010.

BAESSO, M.M.; TEIXEIRA, M.M.; RODRIGUES JUNIOR, F.A.; MAGNO JUNIOR, R.G.; FERNANDES, H.C. Avaliação do nível de ruído emitido por um conjunto trator-pulverizador com e sem assistência de ar. Engenharia na Agricultura, Viçosa, v.16, p. 400-407, 2008.

CAMARA, F.T. Biodiesel de dendê em trator agrícola: desempenho em função do tempo de armazenamento e da proporção de mistura na operação de preparo do solo. 2009, 92f. Tese (Doutorado em Ciência do Solo), Faculdade de Ciências Agrárias e Veterinárias, Universidade Estadual Paulista, Jaboticabal.

CONSELHO NACIONALDO MEIO AMBIENTE - CONAMA. RESOLUÇÃO CONAMA $\mathbf{n}^{\circ}$ 16, de 13 de dezembro de 1995. Dispõe sobre os limites máximos de emissão de poluentes para os motores destinados a veículos pesados novos, nacionais e importados, e determina a homologação e certificação de veículos novos do ciclo Diesel quanto ao índice de fumaça em aceleração livre. Diário Oficial da União, Poder Executivo, Brasília, DF, n.249, de 29 de dezembro de 1995, Seção 1, páginas 22877-22878.

\section{CONSELHO NACIONAL DO MEIO AMBIENTE}

- CONAMA. RESOLUÇÃO CONAMA no 251, de 7 de janeiro de 1999. Dispõe sobre os critérios, procedimentos e limites máximos de opacidade da emissão de escapamento dos veículos automotores do ciclo Diesel, em uso no Território Nacional, a serem utilizados em programas de I/M. Diário Oficial da União, Poder Executivo, Brasília, DF, n.7, de 12 de janeiro de 1999, Seção 1, página 97. 
CONDE, A.P. Desempenho de motor ciclo diesel alimentado com biodiesel de óleo de soja e oliva. 2007. 66f. Dissertação (Mestrado em Engenharia Agrícola, Máquinas e Automação Agrícola)Universidade Federal de Lavras, Lavras, 2007.

DEWANGAN, K.N.; PRASANNAKUMAR, G.V.; TEWARI, V.K. Noise characteristics of tractors and health effect on farmers. Applied Acoustics, London, v.66, p.1049-1062, 2005.

HOMIS CONTROLE E INSTRUMENTAÇÃO LTDA. Decibelímetro digital modelo 913 H004353. Manual. São Paulo: Homis, 2009. 106p.

INTERNATIONAL

STANDARD

ORGANIZATION - ISO. Norma ISO 1999.

Acoustics - assessment of occupational noise exposure for hearing conservation purposes. St. Joseph, 1975. não paginado.

LIOTTI, C.G.; LOPES, A.; LIMA, L.P.; CAMARA, F.T.; GUIOTTO, F.A.; KOIKE, G.H.A. Opacidade da fumaça de trator agrícola em função do uso de biodiesel de dendê e das condições climáticas. In: CONGRESSO DE INICIAÇÃO CIENTÍFICA, 22, 2010, Anais... Marília: UNESP, 2010. p.1-4.

LOPES, A.; CÂMARA, F.T.; OLIVEIRA, M.C.J. FURLANI, C.E.A.; SILVA, R.P.; MELLO JÚNIOR, J.G.S. Opacidade da fumaça de trator agrícola utilizando biodiesel em função das condições climáticas no horário de execução do ensaio. In: CONGRESSO BRASILEIRO DE ENGENHARIA AGRÍCOLA, 38, 2009 Anais... Juazeiro(Ba)/Petrolina(PE): SBEA, 2009. p.1-4.

MAZIERO, J.V.G.; CORREA, I.M.; TRIELLI, M.A.; BERNARDI, J.A.; D'AGOSTINHO, M.F. Avaliação de emissões poluentes de um motor diesel utilizando biodiesel de girassol como combustível. Engenharia na Agricultura, Viçosa, v.14, p.287-292, 2006.

MELLO JÚNIOR, J.G.S. Opacidade da fumaça de trator agrícola em função da proporção de mistura de biodiesel/diesel e das condições climáticas no horário de execução do ensaio. 2006. 74f. Monografia (Graduação em Agronomia) Faculdade de Ciências Agrárias e Veterinárias, Universidade Estadual Paulista, Jaboticabal.

MIALHE, L.G. Máquinas Agrícolas: ensaios e certificações. Piracicaba: FEALQ, 1996. 722p.

MINISTÉRIO DO TRABALHOE DO EMPREGO - MTE. Atividades e operações insalubres: NR-15. Disponível: < http://www.mtb.gov.br/ legislacao/normas_regulamentadoras/nr_15.pdf> Acesso em 28 de setembro de 2010a.

MINISTÉRIO DO TRABALHO E DO EMPREGO - MTE. Equipamento de proteção individual - EPI - NR-6. Disponível em: < http://www. mte.gov.br/legislacao/normas_regulamentadoras/ nr_06.pdf>. Acesso em 28 de setembro de 2010b.

TABILE, R.A. LOPES, A.; DABDOUB, M.J.; CAMARA, F.T.; FURLANI, C.E.A.; SILVA, R.P. Biodiesel de mamona no diesel interior e metropolitano em trator agrícola. Engenharia Agrícola, Jaboticabal, v.29, p.412-423, 2009.

TECNOMOTOR - $\quad$ TECNOMOTOR ELETRÔNICA DO BRASIL LTDA. TM 133 Opacímetro. Manual de Operação. São Carlos: Tecnomotor, 2007a. Ed. 10/07, 12p.

TECNOMOTOR

TECNOMOTOR ELETRÔNICA DO BRASIL LTDA. Software IGOR. Manual de Operação. São Carlos: Tecnomotor, 2007b. Ed. 08/07, 64p.

TECNOMOTOR

TECNOMOTOR ELETRÔNICA DO BRASIL LTDA. TM 525/2 Tacometro Universal. Manual de Instruções. São Carlos: Tecnomotor, 2007c. Ed. 09/07, 12p.

TECNOMOTOR TECNOMOTOR ELETRÔNICA DO BRASIL LTDA. TM 616 Controlador Serial. Manual de Operação. São Carlos: Tecnomotor, 2010. Ed. 07/10, 12p. 